\title{
Degradation of Polypropylene and Jute Fiber-Reinforced Composites Exposed to Natural and Accelerated Aging: Mechanical Properties and Wettability
}

\author{
Paula Bertolino Sanvezzo (D), Fernanda Pereira de Castro Negreiros and Marcia Cristina Branciforti * (DD
}

check for updates

Citation: Sanvezzo, P.B.; Negreiros, F.P.d.C.; Branciforti, M.C.

Degradation of Polypropylene and Jute Fiber-Reinforced Composites Exposed to Natural and Accelerated Aging: Mechanical Properties and Wettability. Chemistry 2021, 3 , 1392-1400. https://doi.org/10.3390/ chemistry3040100

Academic Editor: Pietro Russo

Received: 31 October 2021

Accepted: 20 November 2021

Published: 23 November 2021

Publisher's Note: MDPI stays neutral with regard to jurisdictional claims in published maps and institutional affiliations.

Copyright: (c) 2021 by the authors. Licensee MDPI, Basel, Switzerland. This article is an open access article distributed under the terms and conditions of the Creative Commons Attribution (CC BY) license (https:/ / creativecommons.org/licenses/by/ $4.0 /)$.
Department of Materials Engineering, São Carlos School of Engineering, University of São Paulo, Avenida Trabalhador São-Carlense, 400, São Carlos 13566-590, Brazil; paula.sanvezzo@usp.br (P.B.S.); fernanda.negreiros@usp.br (F.P.d.C.N.)

* Correspondence: marciacb@sc.usp.br; Tel.: +55-16-33738672

\begin{abstract}
Population growth and the way resources are being exploited are directly affecting the environment. The natural fiber market, for example, is worth billions of dollars and a huge amount of the fibers becomes waste. This considerable amount of waste motivates the study of the fibers as a reinforcement in polymeric matrix, which benefits both the environmental sustainability and technical-commercial development of new materials with good properties and reduced cost. In this study, jute fiber-reinforced composites previously manufactured from an industrial waste (W), polypropylene, compatibilizer, and nano-calcium carbonate $(\mathrm{N})$, were exposed to natural and accelerated aging. The composites were tested by infrared spectroscopy, contact angle (CA) measurement, and tensile test. Infrared analysis showed greater oxidative degradation after accelerated aging. All CA values continued above $90^{\circ}$ after natural aging. Among all compositions, the ones with the presence of $\mathrm{N}$ had the highest $\mathrm{CA}$ values, showing that $\mathrm{N}$ acted as a waterproofing agent. After accelerated aging, a significant decrease in all CA values was observed. The composites did not show significant variation in the elastic modulus after either aging. Deformation at break decreased significantly for compositions with no jute fiber in both aging programs. No remarkable reduction was observed in the compositions with jute fibers.
\end{abstract}

Keywords: accelerated weathering; natural weathering; recycling; industrial waste; natural fiber; infrared spectroscopy

\section{Introduction}

Natural fibers have a huge market that moves billions of dollars every year [1]. Despite several studies having been conducted on the reuse of natural fibers waste [2-4], there is still a long way to go, especially when it comes to specific companies' issues. The maintenance of industrial sustainability is extremely dependent on the correct application of these natural resources. Therefore, this paper addresses the reuse of a jute-fiber and polypropylene waste of a carpet manufacturer located in São Carlos, Brazil, whose processes generate textile residues that are currently landfilled.

Natural fiber-reinforced composites are becoming an important area of development for transport, marine, and construction industries [5]. The possible applications for these composite materials include window and doorframes, furniture, railroad sleepers, automotive panels, gardening items, packaging, etc. In general, applications do not require very high mechanical resistance, but instead, reduce the purchasing and maintenance costs [6]. When compared to synthetic fibers, such as glass fiber, their most important advantages are lower density, sound absorption, and vibration damping [7,8]. They also reduce the wear of screws and barrels of processing equipment compared to commonly used glass fibers [9]. Despite the attractive attributes, they have some drawbacks, such as high moisture uptake, 
lower mechanical properties compared to synthetic fibers, and low compatibility with nonpolar polymer matrices due to their polar nature $[5,8,10]$.

Plant fibers can be classified based on the source and their physiological properties. Jute fibers are obtained from the stem and are called bast fibers (such as flax, hemp, and kenaf). They can also be divided into primary (grown for the fiber) and secondary (byproduct of plants) utility. Jute fibers are primary utility plant fibers [11]. Nevertheless, the jute fiber used in this study is part of a mixed industrial waste composed of jute and polypropylene; therefore, it should not be treated separately or considered a virgin material.

The use of mineral fillers has been a common practice in the plastics industry to improve mechanical properties and for cost reduction. In the case of micrometric particulates, high filler content (higher than $20 \%$ by volume) is required, while nanometre-sized particles show an increase in mechanical performance at much lower concentrations [12]. In addition, in this study, nano-calcium carbonateis also added to slow the entry of moisture, decreasing the surface wettability of the composite material. When some mineral particle is used as an additive, the pathways for moisture ingress are closed, contributing to a better waterproofing resistance [13].

The mechanical behavior of a thermoplastic composite is closely related to its phase interactions. Good matrix-fiber interfacial adhesion is essential for mechanical stress transfer from the matrix to the reinforcement, consequently improving the mechanical properties of the composites [14]. Interaction and compatibility between the natural polar and hydrophilic jute fiber and the non-polar and hydrophobic polymeric matrix can be improved by adding a compatibilizing agent. Polar maleic anhydride grafted polymers are common compatibilizing agents.

Material selection in the manufacturing of sustainable products plays a vital role in engineering design, and polymer composites are one of such materials which provide ease of processing, productivity, and cost reduction [15]. Considering that the industrial waste is composed of biodegradable natural jute fiber and non-biodegradable plastics-i.e., it has a mixed nature-previous research focused on the development of a durable composite material, with desired high-performance properties. For this purpose, researchers have used nano-calcium carbonate as a mineral filler, in addition to the natural jute fiber reinforcement, and a compatibilizer for improving fiber-matrix interactions [16]. Afterward, another study concentrated on investigating strategies for getting this durable composite material into the market [17] — street furniture was among the highest-rated for the application of the developed material. Therefore, it would be of great interest to carry out degradation tests on these materials to know their behavior under weathering. In this paper, previously manufactured composites composed of polypropylene, a compatibilizer, nano-calcium carbonate, and reinforced with jute fibers from industrial waste, were exposed to natural and accelerated aging. Degradation was assessed by visual analysis and infrared spectroscopy. The specimens were also tested by tensile and contact angle measurement to assess the mechanical properties and wettability of the composites before and after both aging programs.

\section{Materials and Methods}

Polikem Company provided recycled homopolymer polypropylene (PP) of $45 \mathrm{~g} 10 \mathrm{~min}^{-1}$ melt flow index at $230^{\circ} \mathrm{C}$ and $2.16 \mathrm{~kg}$, in accordance with ASTM D1238. WINNOFIL ${ }^{\circledR}$ SPT nano-calcium carbonate $(\mathrm{N})$ of $50-100 \mathrm{\eta m}$ particle size was supplied by Imerys Company. The surface of $\mathrm{N}$ was treated with stearic acid for decreasing particle-particle interaction and increasing matrix adhesion. DuPont Company donated the compatibilizer (C) Fusabond ${ }^{\circledR}$ M603, based on random ethylene copolymers and maleic anhydride. Tapetes São Carlos carpet company, Brazil, provided the industrial waste (W). W is a refuse of internal automotive components composed of approximately $40 \mathrm{wt} . \%$ jute fibers and $60 \mathrm{wt} . \%$ polypropylene (less than $1 \mathrm{wt} . \%$ of polyester impurities), i.e., it has a mixed nature. 


\subsection{Thermogravimetric Analysis of Industrial Waste}

Thermogravimetric analysis (TGA) of industrial waste (W) was conducted on model Pyris 1 TGA Perkin Elmer. The measurement was taken from $30^{\circ} \mathrm{C}$ to $700{ }^{\circ} \mathrm{C}$ at $20^{\circ} \mathrm{C} \mathrm{min}{ }^{-1}$ heating rate, under $20 \mathrm{~mL} \mathrm{~min}^{-1} \mathrm{~N}_{2}$ gas flow.

\subsection{Manufacture of Composites}

The dry components were mixed in a B\&P Process Equipment and Systems corotational twin-screw extruder (MT19TC) of $19 \mathrm{~mm}$ screw diameter (D) and $25 \mathrm{~L}$ (length)/D. Aiming at a better dispersion of $\mathrm{N}$ particles in the matrix, a masterbatch (M) of $30 \mathrm{wt} . \%$ $\mathrm{N}$ and $70 \mathrm{wt} . \%$ PP was initially prepared. Table 1 shows the composition of all processed samples. The composites were injection-molded in a model Allrounder 270 400-100 Arburg machine. The dimension of the specimens followed Type I geometry, according to ASTM D638. All extruded pellets and injection-molded samples were dried at $40{ }^{\circ} \mathrm{C}$ under vacuum for $24 \mathrm{~h}$ before tests [16].

Table 1. Samples composition. PP: polypropylene; W: industrial waste; M: masterbatch; N: nanocalcium carbonate; C: compatibilizer.

\begin{tabular}{ccccc}
\hline Sample & PP (wt.\%) & W (wt.\%) & N (wt.\%) & C (wt.\%) \\
\hline PP & 100 & - & - & - \\
PPM & 90 & - & 10 & - \\
PPW & 50 & 50 & - & - \\
PPCW & 49 & 50 & - & 1 \\
PPMW & 40 & 50 & 10 & - \\
PPMCW & 39 & 50 & 10 & 1 \\
\hline
\end{tabular}

\subsection{Natural Aging}

The natural aging was performed following D1435 by exposing the specimens to the natural weathering for 168 days ( 24 weeks), resulting in $4032 \mathrm{~h}$ of exposure. The test was conducted from May to November 2019 in a weather station of University of São Paulo, São Carlos, Brazil $\left(21^{\circ} 59^{\prime} 54.2^{\prime \prime} \mathrm{S} 47^{\circ} 55^{\prime} 39.7^{\prime \prime} \mathrm{W}\right)$. The specimens were placed at $45^{\circ}$ to the horizontal and the backside to the north, in an in-house-made apparatus (easel) [18].

\subsection{Accelerated Aging}

The accelerated aging was performed following ASTM G151in special equipment with UV-A Philips lamps model Cleo performance $80 \mathrm{WR}$, and 315 to $400 \mathrm{~nm}$ emission range. The aging program consisted of cycles of $22 \mathrm{~h}$ irradiation per day and $24 \mathrm{~h}$ of moisture and heat exposure. The specimens were exposed to UV-A light $22 \mathrm{~h}$ per day, at $50^{\circ} \mathrm{C}$, for 30 days, resulting in $660 \mathrm{~h}$ of UV-A exposure and $720 \mathrm{~h}$ of heat and moisture exposure [16].

\subsection{Infrared Spectroscopy}

Infrared spectra of the samples before and after natural and accelerated aging were recorded by PerkinElmer Spectrum 1000 equipment and attenuated total reflection method in the $4000-550 \mathrm{~cm}^{-1}$ range. The samples were directly placed onto the ZnSe ATR cell and sixteen scans were averaged at $\pm 4 \mathrm{~cm}^{-1}$ resolution.

\subsection{Contact Angle Measurements}

Contact angle (CA) measurements were performed on CAM 101 equipment and CAM 2008 software version 4.04, both commercialized by KSV Instruments. A $1 \mathrm{~cm}^{3}$ syringe deposited water droplets on the specimen surface, and 40 images of each droplet were recorded every $16 \mathrm{~ms}$. The mean contact angle was calculated for at least 2 drops on each sample. 


\subsection{Tensile Tests}

Tensile tests were conducted in specimens according to ASTM D638-10 by model 5969 Instron Universal Test equipment and Bluehill Data Processing Software equipped with a

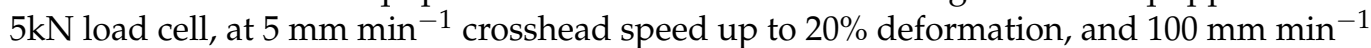
until rupture. Two different speeds were used to fracture the specimens within the time limit established by the standard (from $30 \mathrm{~s}$ to $5 \mathrm{~min}$ ).

\section{Results and Discussion}

\subsection{Thermal Stability of Industrial Waste}

Thermogravimetric analysis (TGA) was carried out to evaluate the thermal stability of the industrial waste $(\mathrm{W}=$ composed of jute fiber and PP) [12]. Figure 1 shows both TG and DTG curves. The first mass loss $\left(30\right.$ to $\left.100{ }^{\circ} \mathrm{C}\right)$ is due to the evaporation of residual water. Second and third mass losses refer mainly to hemicellulose (starting point: $250{ }^{\circ} \mathrm{C}$; maximum decomposition: $318{ }^{\circ} \mathrm{C}$ ) and cellulose (starting point: $343{ }^{\circ} \mathrm{C}$; maximum decomposition: $392{ }^{\circ} \mathrm{C}$ ) thermal decomposition, respectively. The fourth is due to the decomposition of polypropylene and polyester impurities (starting point: $422{ }^{\circ} \mathrm{C}$; maximum decomposition: $497^{\circ} \mathrm{C}$ ). The last mass loss stage, which extends up to $700{ }^{\circ} \mathrm{C}$, i.e., maximum analysis temperature, is associated with lignin. This structural component shows the highest thermal stability among the natural fiber components [19]. The composition, even the thermal decomposition, of natural fibers varies depending on several factors, including species, age and the environment. Yao et al. [20] analyzed the thermal decomposition processes of natural fibers commonly used in the polymer composite industry by TGA and observed jute fibers show onset decomposition temperature of $205.1^{\circ} \mathrm{C}$ and maximum decomposition rate of $283.1{ }^{\circ} \mathrm{C}$. The $\mathrm{W}$ is thermally stable under used processing conditions.

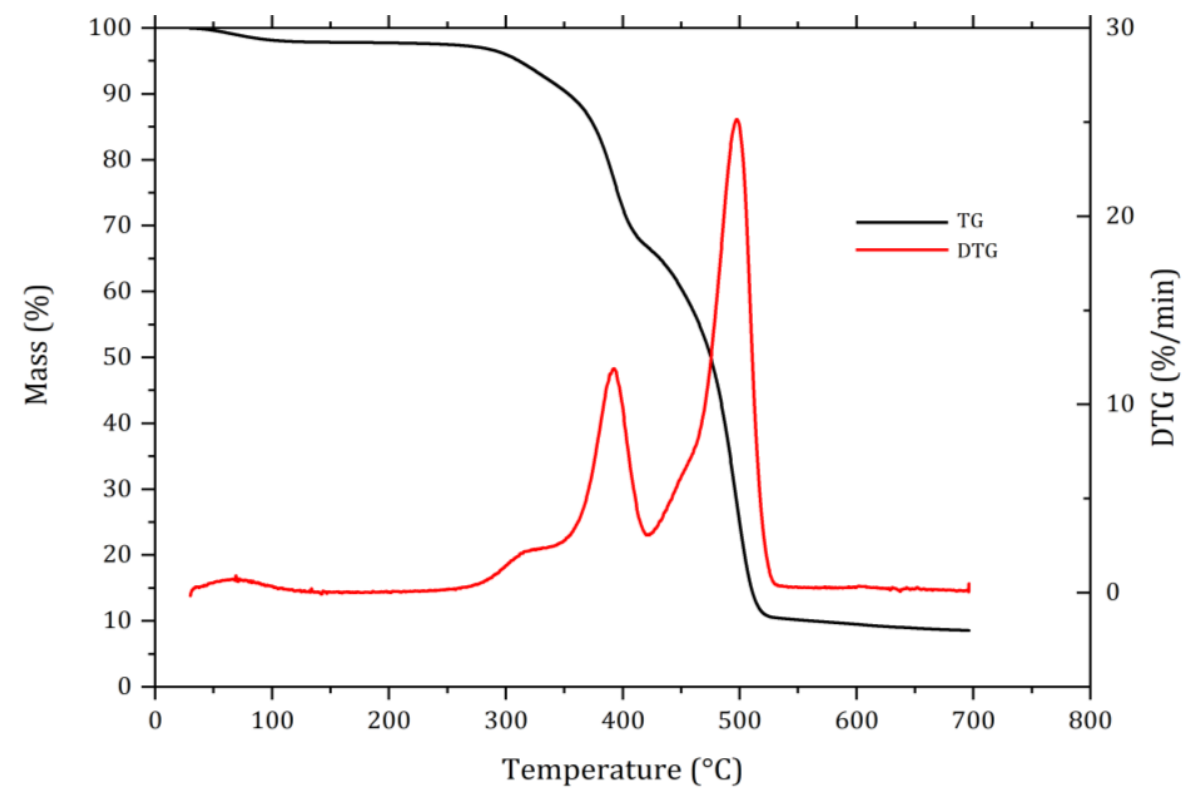

Figure 1. TGA curves of industrial waste (W). Reprinting with permission from ref. [16]. Copyright 2021 Elsevier.

\subsection{Visual Non-Destructive Test}

Figure 2 displays an image of the PPMCW sample before (0 days), and after natural (168 days) and accelerated (30 days) aging. The first analysis was based on the visual aspect of the samples before and after the two aging programs. As expected, samples exposed to weathering showed surface damage characterized by higher opacity, rougher surface, and the presence of whitish regions after aging. Although the three damage effects have shown up on both aging programs, all of them were more severe on accelerated aging. 


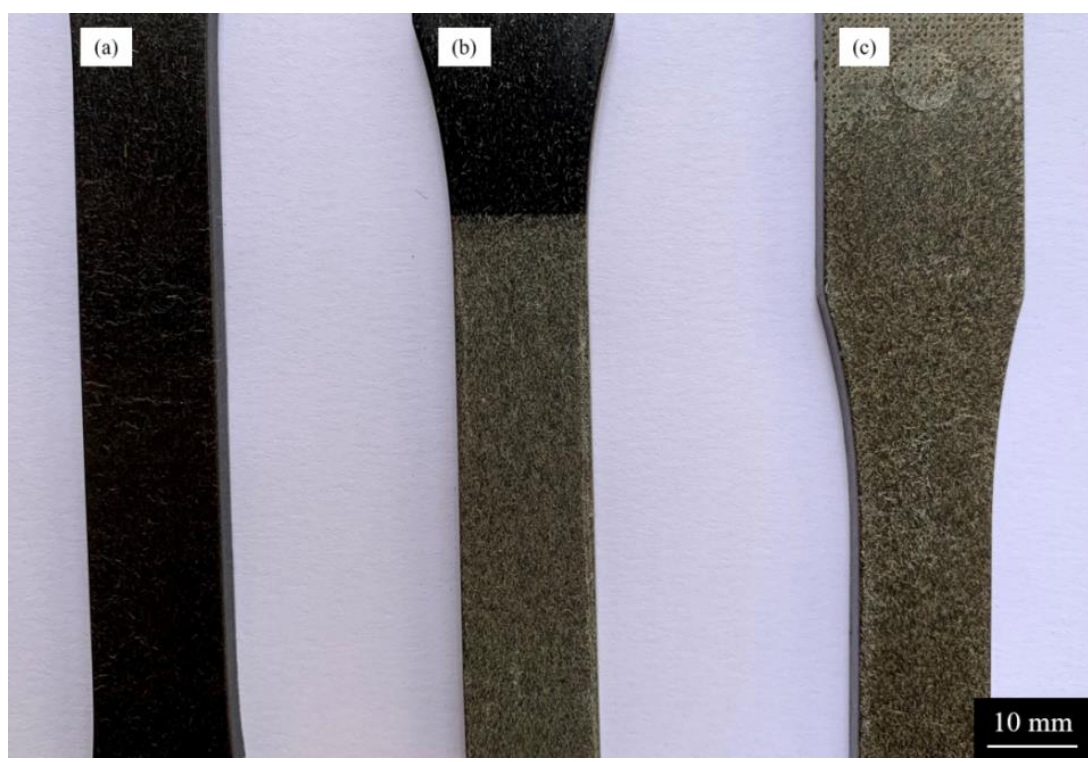

Figure 2. Visual non-destructive test of PPMCW sample (a) before, (b) after natural, and (c) accelerated aging.

\subsection{Infrared Spectroscopy}

Infrared analysis was performed on samples before and after exposure to natural and accelerated aging to investigate the presence of functional groups related to material oxidative degradation. Figure 3 shows the infrared spectra of PPMCW sample before and after the aging programs. The major absorption band analyzed for the current study appears at about $1715 \mathrm{~cm}^{-1}$ after UV irradiation assigned to the stretching vibrations of carbonyl group $(\mathrm{C}=\mathrm{O})$. Another band at $3400 \mathrm{~cm}^{-1}$ corresponds to the stretching vibrations of hydroxyl group (O-H) [21]. According to the tested conditions, the relative intensities of the carbonyl and hydroxyl bands are greater after accelerated aging exposure in comparison to natural aging, suggesting the material suffers more degradation after accelerated aging. Similar behavior was observed for the other studied samples.

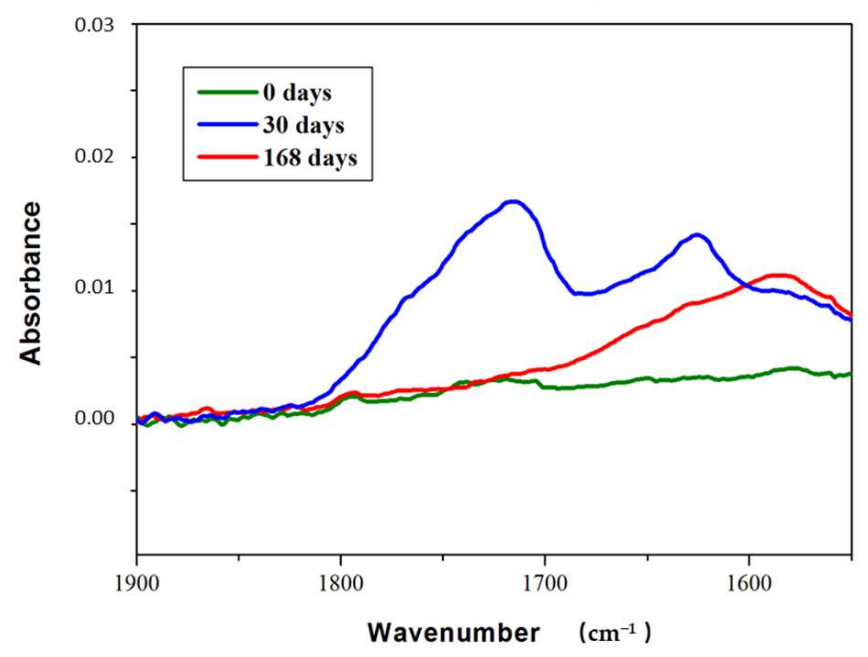

(a)

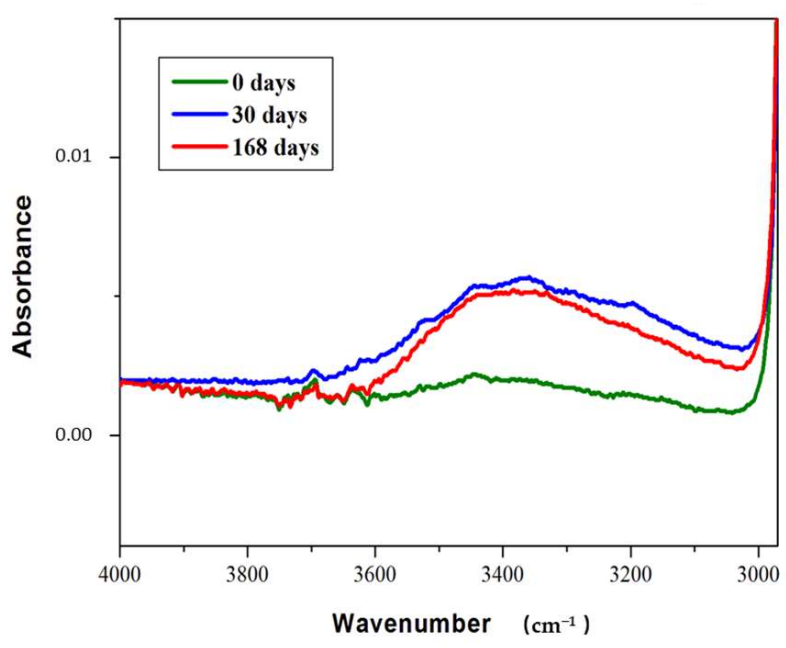

(b)

Figure 3. Infrared spectra of PPMCW sample before (0 days), after natural (168 days), and accelerated (30 days) aging (a) in the domain $1900-1550 \mathrm{~cm}^{-1}$ and (b) in the domain $4000-3000 \mathrm{~cm}^{-1}$. 


\subsection{Wettability}

Figure 4 displays contact angle (CA) measurements performed in all compositions before ( 0 days) and after natural (168 days) and accelerated (30 days) aging. Before exposure, all samples showed CA values above $90^{\circ}$, indicating hydrophobicity (poor wetting) [22], a highly relevant result from a commercial point of view. After natural aging (168 days), the CA values continued above $90^{\circ}$, however all of them showed a slight rise in comparison to non-degraded samples (0 days). This was an unexpected result, since degradation on the specimens' surface, caused by weathering, makes it porous, thus favoring hydrophilicity. This result may be associated with an experimental error since the measurements were performed at different times. Nevertheless, this result is very significant since even after 168 days of outdoor exposure, the composites maintained their hydrophobicity at a certain level. Among all compositions, the ones with the presence of N (PPM, PPMW, and PPMCW samples) had the highest $\mathrm{CA}$ values, showing that $\mathrm{N}$ acted as a waterproofing agent, as expected.

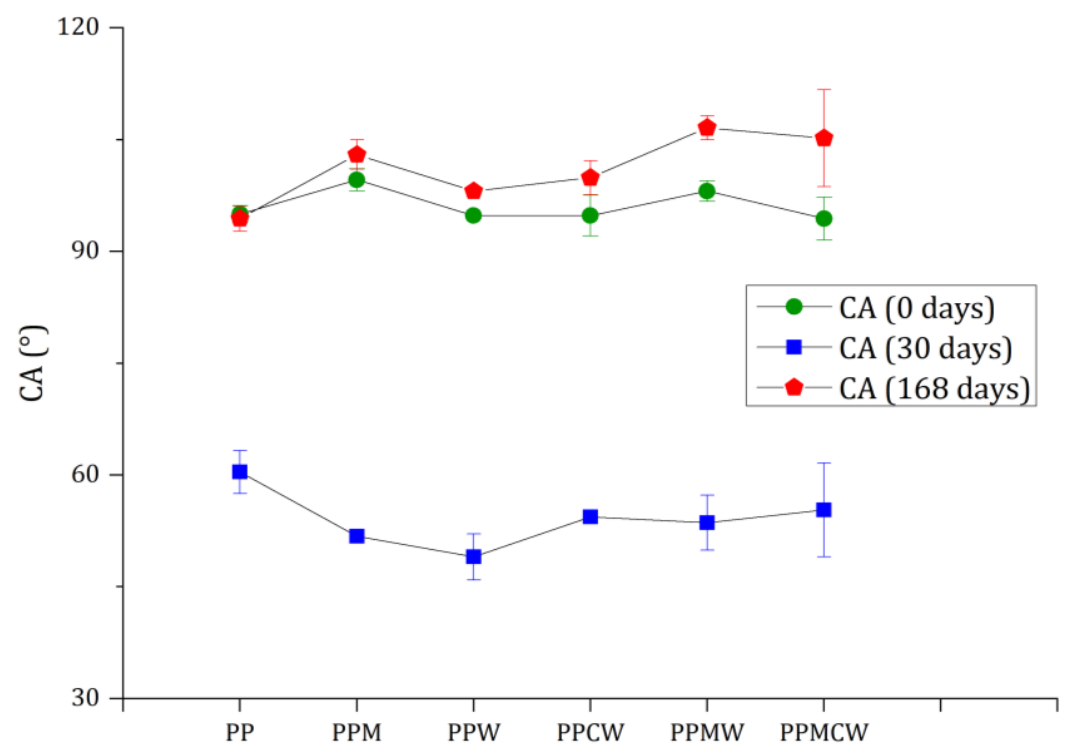

Figure 4. Water contact angle (CA) values of samples before (0 days), after natural (168 days), and accelerated (30 days) aging.

After accelerated aging (30 days), a significant decrease in all CA values was observed, demonstrating that the accelerated aging program exposed the materials to much more severe conditions when compared to the natural aging exposure.

\subsection{Tensile Properties}

Tensile tests were performed in all six samples before and after natural and accelerated aging for comparative results. Figure 5 a shows yield stress $(\sigma)$, Figure $5 \mathrm{~b}$ shows elastic modulus (E), and Figure $5 \mathrm{c}$ shows deformation at break $(\varepsilon)$, of the samples before ( 0 days), after natural (168 days), and accelerated (30 days) aging. Results for yield stress before aging show no significant variation for the samples, and the reinforcements did not increase the yield point, probably due to the low adhesion between the natural fiber and the matrixonce it has reached the yield stress limit of the matrix, it started the plastic deformation of the composites. The presence of jute fibers led to a $135 \%$ improvement in the elastic modulus and decreased the deformation at break from $435 \%$ to $5 \%$. The presence of nanocalcium carbonate $(\mathrm{N})$ increased elastic modulus by $18 \%$ and decreased deformation at break from $435 \%$ to $61 \%$ [16]. 


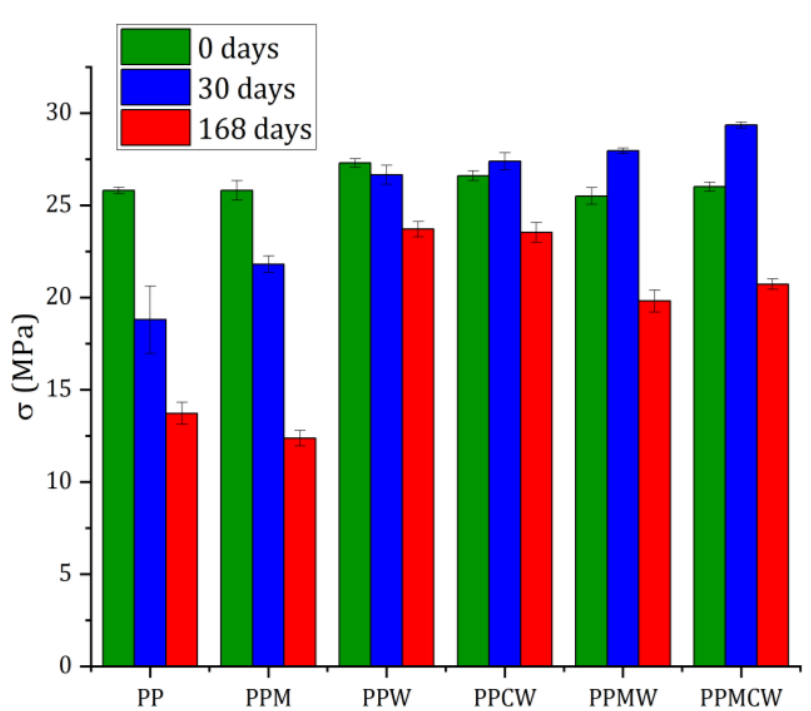

(a)

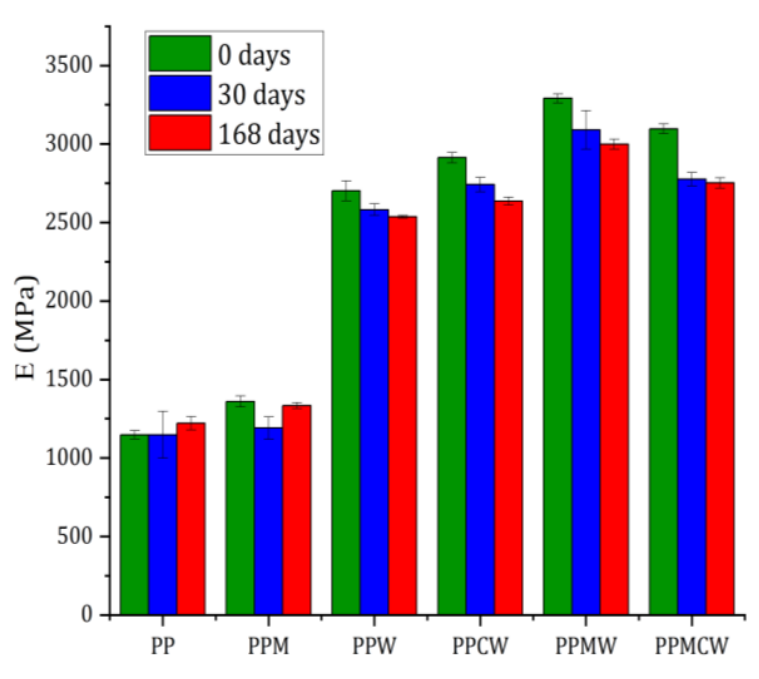

(b)

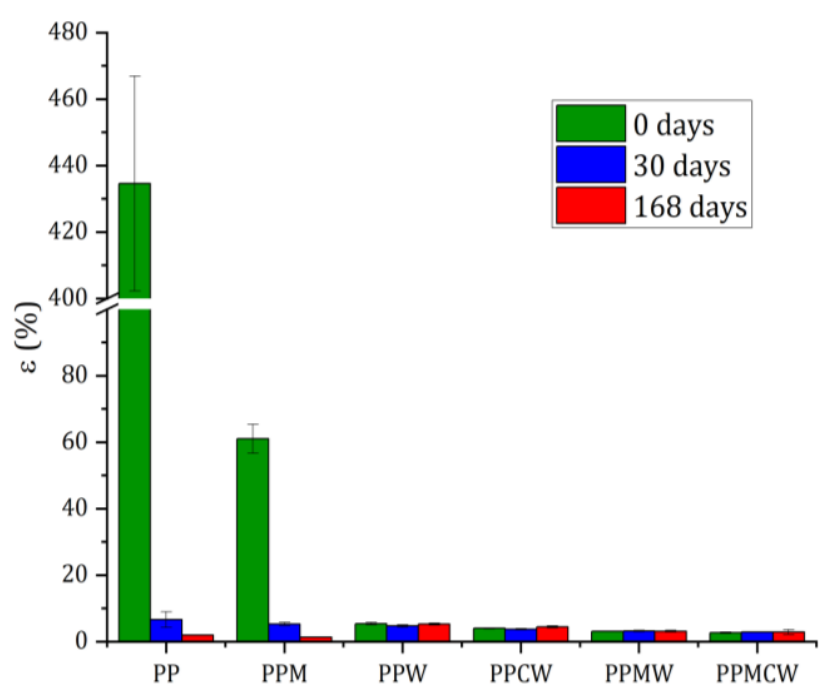

(c)

Figure 5. (a) Yield stress $(\sigma),(\mathbf{b})$ elastic modulus (E), and (c) deformation at break $(\varepsilon)$ of samples before (0 days), after natural (168 days), and accelerated (30 days) aging.

According to Figure 5a, results of yield stress after natural aging (168 days) indicated a certain decrease for all samples, while after accelerated aging (30 days) it showed a slight decrease only in the compositions with no jute fiber (PP and PPM samples). The samples did not show significant variation in the elastic modulus after either aging, Figure $5 \mathrm{~b}$. The deformation at break decreased significantly for compositions with no jute fiber in both natural and accelerated aging programs, as expected. However, no remarkable reduction was observed in the compositions with jute fibers, as shown in Figure 5c. These are promising results since it is not desirable to have any decrease in mechanical properties when exposing a product to weathering.

Complementary scanning electron microscopy (SEM) performed on samples before aging (0 days) was recently published [16]. The SEM micrograph of criofractured surfaces has shown some fiber pull-out voids even in samples with the presence of compatibilizer, corroborating the mechanical test results. 


\section{Conclusions}

The visual, infrared and contact angle analyses showed that damage effects and degradation were more severe on samples after accelerated aging than the natural one, according to the tested conditions. The use of nano-calcium carbonate not only decreased wettability, but also improved the mechanical properties. Despite results of yield stress showing a certain decrease after both aging, the samples did not show significant variation in the elastic modulus. The variation in deformation at break after both aging programs had significant decrease only for compositions with no jute fiber, that is, compositions with jute fibers did not show remarkable reduction in their ability to deform plastically before breaking. Probably due to the use of low concentration of compatibilizer, the adhesion between matrix and fiber was not effective, as shown by tensile tests results. Nevertheless, the mechanical and waterproof properties have considerably increased (PPMW showed the best average results among compositions with waste). This result is economically positive, since the compatibilizer is the most expensive component. Regardless of expected decrease in the mechanical and waterproof properties after aging, the average results are very favorable, especially in the construction and infrastructure markets, regarding outdoor applications and products exposed to low mechanical loads.

Author Contributions: Investigation, P.B.S. and F.P.d.C.N.; supervision, conceptualization, and funding acquisition, M.C.B.; writing —original draft preparation and editing, P.B.S. and M.C.B. All authors have read and agreed to the published version of the manuscript.

Funding: This research was funded by Coordination of Higher Level Staff Improvement (CAPES) (finance code 001).

Institutional Review Board Statement: Not applicable.

Informed Consent Statement: Not applicable.

Data Availability Statement: Not applicable.

Acknowledgments: The authors acknowledge A. Francisco for the industrial waste donation, J. A. Sousa and O. F. Sousa Jr. for the extrusion, L. H. C. Mattoso and A. R. Pina for the injection molding, E. M. Mendiondo for the use of weather station, and R. G. Pereira, for all technical support.

Conflicts of Interest: The authors declare no conflict of interest.

Sample Availability: Samples of the compounds are not available from the authors.

\section{References}

1. Global Market Insights Global Market Insights. Gmi 2016, 104. Available online: https://www.gminsights.com/industryanalysis / cellulose-fiber-market/ (accessed 29 October 2021).

2. Hassan, T.; Jamshaid, H.; Mishra, R.; Khan, M.Q.; Petru, M.; Novak, J.; Choteborsky, R.; Hromasova, M. Acoustic, mechanical and thermal properties of green composites reinforced with natural fiberswaste. Polymers 2020, 12, 654. [CrossRef] [PubMed]

3. Saad, M.; Agwa, I.S.; Abdelsalam Abdelsalam, B.; Amin, M. Improving the brittle behavior of high strength concrete using banana and palm leaf sheath fibers. Mech. Adv. Mater. Struct. 2020, 1-10. [CrossRef]

4. Busuioceanu, I.I.; Enăchescu, G.-L.; Baciu, F.; Dinu, G.; Ştefănescu, M.F. Determination of mechanical behavior of new biocomposites. AIP Conf. Proc. 2018, 1932, 030004. [CrossRef]

5. Bourmaud, A.; Shah, D.U.; Beaugrand, J.; Dhakal, H.N. Property changes in plant fibres during the processing of bio-based composites. Ind. Crops Prod. 2020, 154, 112705. [CrossRef]

6. Sanjay, M.R.; Madhu, P.; Jawaid, M.; Senthamaraikannan, P.; Senthil, S.; Pradeep, S. Characterization and properties of natural fiber polymer composites: A comprehensive review. J. Clean. Prod. 2018, 172, 566-581. [CrossRef]

7. Prabhakaran, S.; Krishnaraj, V.; Senthil Kumar, M.; Zitoune, R. Sound and Vibration Damping Properties of Flax Fiber Reinforced Composites. Procedia Eng. 2014, 97, 573-581. [CrossRef]

8. Sanjay, M.R.; Siengchin, S.; Parameswaranpillai, J.; Jawaid, M.; Pruncu, C.I.; Khan, A. A comprehensive review of techniques for natural fibers as reinforcement in composites: Preparation, processing and characterization. Carbohydr. Polym. 2019, 207, 108-121. [CrossRef]

9. Bledzki, A.K.; Franciszczak, P.; Osman, Z.; Elbadawi, M. Polypropylene biocomposites reinforced with softwood, abaca, jute, and kenaf fibers. Ind. Crops Prod. 2015, 70, 91-99. [CrossRef] 
10. Fajardo Cabrera de Lima, P.F.C.; Santana, R.M.C.; Chamorro Rodríguez, C.D. Influence of Coupling Agent in Mechanical, Physical and Thermal Properties of Polypropylene/Bamboo Fiber Composites: Under Natural Outdoor Aging. Polymers 2020, 12, 929. [CrossRef] [PubMed]

11. Vinod, A.; Sanjay, M.R.; Suchart, S.; Jyotishkumar, P. Renewable and sustainable biobased materials: An assessment on biofibers, biofilms, biopolymers and biocomposites. J. Clean. Prod. 2020, 258, 120978. [CrossRef]

12. Wu, C.L.; Zhang, M.Q.; Rong, M.Z.; Friedrich, K. Tensile performance improvement of low nanoparticles filled-polypropylene composites. Compos. Sci. Technol. 2002, 62, 1327-1340. [CrossRef]

13. Luthra, P.; Singh, R.; Kapur, G.S. Preparation and studies of pigeon pea stalk/polypropylene composites with and without compatibilizer. Polym. Polym. Compos. 2019, 27, 337-346. [CrossRef]

14. Godara, A.; Raabe, D.; Bergmann, I.; Putz, R.; Muller, U. Influence of additives on the global mechanical behavior and the microscopic strain localization in wood reinforced polypropylene composites during tensile deformation investigated using digital image correlation. Compos. Sci. Technol. 2009, 69, 139-146. [CrossRef]

15. Thyavihalli Girijappa, Y.G.; Mavinkere Rangappa, S.; Parameswaranpillai, J.; Siengchin, S. Natural Fibers as Sustainable and Renewable Resource for Development of Eco-Friendly Composites: A Comprehensive Review. Front. Mater. 2019, 6, 1-14. [CrossRef]

16. Sanvezzo, P.B.; Branciforti, M.C. Recycling of industrial waste based on jute fiber-polypropylene: Manufacture of sustainable fiber-reinforced polymer composites and their characterization before and after accelerated aging. Ind. Crops Prod. 2021, 168, 113568. [CrossRef]

17. Cobra, R.; Sanvezzo, P.; Branciforti, M.; Mascarenhas, J. Circular technology roadmapping (TRM): Fostering sustainable material development. Sustainability 2021, 13, 7036. [CrossRef]

18. de Castro Negreiros, F.P.; Sanvezzo, P.B.; Branciforti, M.C. Propriedades de compósitos fabricados com resíduo industrial, projeto e prospeç̧ão de custo de produção de mobiliário urbano com conceito de economia circular. In A Química nas Áreas Natural, Tecnológica e Sustentável; Atena Editora: Ponta Grossa, Brazil, 2020; pp. 258-276.

19. Brebu, M.; Vasile, C. Thermal degredation of Lignin-A Review. Cellul. Chem. Technol. 2010, 44, 353-363. [CrossRef]

20. Yao, F.; Wu, Q.; Lei, Y.; Guo, W.; Xu, Y. Thermal decomposition kinetics of natural fibers: Activation energy with dynamic thermogravimetric analysis. Polym. Degrad. Stab. 2008, 93, 90-98. [CrossRef]

21. Philippart, J.-L.; Sinturel, C.; Arnaud, R.; Gardette, J.-L. Influence of the exposure parameters on the mechanism of photooxidation of polypropylene. Polym. Degrad. Stab. 1999, 2, 213-225. [CrossRef]

22. Lin, Y.; Chen, H.; Chan, C.M.; Wu, J. Effects of coating amount and particle concentration on the impact toughness of polypropylene $/ \mathrm{CaCO}_{3}$ nanocomposites. Eur. Polym. J. 2011, 47, 294-304. [CrossRef] 